3.

Derecho penal 

Revista de Derecho

de la Pontificia Universidad Católica de Valparaíso

XXXI (Valparaíso, Chile, 2 Semestre de 2008)

[pp. 357 - 366]

\title{
¿CONSTITUYE UN ORDEN DE PRELACIÓN EL LISTADO DE CAUSAS DE SOBRESEIMIENTO DEFINITIVO DEL ARTÍCULO 250 DEL “CÓDIGO PROCESAL PENAL”?
}

[Does the List of Causes of Definite Stay of Proceedings of Article 250

of the "Criminal Procedural Code" Constitute an Order of Precedence?]

\author{
Guillermo Oliver Calderón* \\ Pontificia Universidad Católica de Valparaíso
}

\begin{abstract}
RESUMEN
El artículo $250 \mathrm{CPP}$. contiene un listado de causas de sobreseimiento definitivo en el proceso penal. Es posible que al cerrar el fiscal su investigación, los antecedentes recopilados permitan sostener que se encuentra acreditada la concurrencia de los requisitos de más de una de dichas causas. En tal situación se plantea el problema de decidir si el sobreseimiento definitivo puede decretarse por cualquiera de los motivos concurrentes, a elección del tribunal, o si debe darse preferencia a unos sobre otros. Esgrimiendo varios argumentos, el autor concluye que hay un orden de prelación en el listado de causas de sobreseimiento definitivo, de modo que la concurrencia de una de ellas excluye la posibilidad de
\end{abstract}

\begin{abstract}
Article 250 of the Criminal Procedural Code contains a list of causes of definite stay of proceedings in the criminal process. It is possible that, when the prosecutor closes its enquiry, the information gathered allows the assertion that the concurrence of more than one of the requirements of said causes is certified. In such situation, the problem whether the definite stay of proceedings may be decreed by any of the concurrent reasons, as chosen by the court, or preference should be given to some over others, is stated. Based on several arguments, the author concludes that there is an order of precedence in the list of causes of definite stay of proceedings, so that the concurrence of one of them
\end{abstract}

* Doctor en Derecho por la Universidad de Barcelona. Profesor Adjunto de Derecho Penal y Derecho Procesal Penal de la Facultad de Derecho de la Pontificia Universidad Católica de Valparaíso. Dirección postal: Facultad de Derecho de la Pontificia Universidad Católica de Valparaíso, Avenida Brasil 2950, Valparaíso, Chile. Dirección electrónica: guillermo.oliver@ucv.cl 
decretar el sobreseimiento por alguna de las siguientes.

Palabras Clave: Sobreseimiento - Sobreseimiento definitivo - Prescripción - Responsabilidad penal Extinción de responsabilidad penal. excludes the possibility of decreeing the stay of proceedings due to some of the following.

KEYWORDS: Stay of proceedings Definite Stay of proceedings - Time bar - Criminal responsibility-Termination of criminal responsibility.

\section{INTRODUCCIÓN}

Tal como su título lo indica, el objetivo de este breve trabajo es determinar si el listado de causas de sobreseimiento definitivo del artículo 250 CPP. constituye un orden de prelación, de modo que el establecimiento de la concurrencia de los requisitos de una de ellas excluya la posibilidad de decretar el sobreseimiento por alguna de las siguientes, o si no lo constituye, de modo que verificada la presencia de los requisitos de dos o más de dichas causas, pueda decretarse el sobreseimiento por cualquiera de ellas.

\section{EXAMEN DE LAS CAUSAS DE SOBRESEIMIENTO DEFINITIVO}

El artículo $250 \mathrm{CPP}$. incluye el listado de causas por las cuales es posible decretar el sobreseimiento definitivo ${ }^{1}$. El tenor de dicha disposición es el siguiente: "Sobreseimiento definitivo. El juez de garantía decretará el sobreseimiento definitivo: a) Cuando el hecho investigado no fuere constitutivo de delito;/b) Cuando apareciere claramente establecida la inocencia del imputado;/ c) Cuando el imputado estuviere exento de responsabilidad criminal en conformidad al artículo 10 del Código Penal o en virtud de otra disposición legal;/ d) Cuando se hubiere extinguido la responsabilidad penal del imputado por algunos de los motivos establecidos en la ley;/ e) Cuando sobreviniere un hecho que, con arreglo a la ley, pusiere fin a dicha responsabilidad, $y / \mathrm{f}$ ) Cuando el hecho de que se tratare hubiere sido materia de un procedimiento penal en el que hubiere recaído sentencia firme respecto del imputado. [inciso $2^{\circ}$ ] El juez no podrá dictar sobreseimiento definitivo respecto de los delitos que,

\footnotetext{
${ }^{1}$ En todo caso, a lo largo del Código Procesal Penal existen varias situaciones en las que se prevé el sobreseimiento definitivo, como por ejemplo, cuando el fiscal no comparece a la llamada audiencia de apercibimiento para cerrar la investigación o, compareciendo, se niega a declararla cerrada o, cerrándola, no formula acusación dentro de los diez días siguientes (incisos $3^{\circ}$ y $5^{\circ}$ del artículo 247). Pero todos estos casos son posibles de ser subsumidos en alguna de las causas del listado del artículo 250. Así, CASTro Jofré, Introducción al Derecho procesal penal chileno (Santiago, LexisNexis, 2006), p. 355.
} 
conforme a los tratados internacionales ratificados por Chile y que se encuentren vigentes, sean imprescriptibles o no puedan ser amnistiados, salvo en los casos de los números $1^{\circ}$ y $2^{\circ}$ del artículo 93 del Código Penal'.

El primer motivo de sobreseimiento definitivo, consistente en que el hecho investigado no constituye delito, puede concurrir en dos situaciones. La primera se verifica cuando de los antecedentes de la investigación del fiscal resulta que no existe el hecho material que dio lugar a la indagación. Si agotada la investigación no ha podido establecerse su existencia, no tiene razón de ser la continuación del proceso, pues falta el elemento principal del juicio penal, cual es la comprobación del hecho punible; en otras palabras, no existe el "cuerpo del delito"2. Es cierto que el artículo 250 CPP. no consagra explícitamente, como causa de sobreseimiento definitivo, una similar a la contenida en el número $1^{\circ}$ del artículo 408 del antiguo Código de Procedimiento Penal, que tenía lugar "cuando, en el sumario, no aparezcan presunciones de que se haya verificado el hecho que dio motivo a formar la causa" . Pero ello no es un obstáculo que impida concluir que si el fiscal, al cerrar su investigación, se convence de que el hecho investigado nunca ocurrió, tenga que solicitar el sobreseimiento definitivo por el motivo de la letra a) del citado artículo $250 \mathrm{CPP}$. Es obvio que si el hecho investigado jamás tuvo lugar, no es constitutivo de delito. Y la segunda situación en la que puede darse esta primera causa de sobreseimiento definitivo -que el hecho investigado no fuere constitutivo de delito- tiene lugar cuando concurre una eximente de responsabilidad penal. Doctrinalmente, se acostumbra definir al delito como una conducta típica, antijurídica y culpablemente ejecutada ${ }^{4}$. En consecuencia, un hecho será no constitutivo de delito cuando alguno de estos elementos no concurra; en otras palabras, cuando se presente una eximente. Y como la letra c) del artículo $250 \mathrm{CPP}$. contempla otro motivo de sobreseimiento definitivo que tiene lugar cuando el imputado estuviere exento de responsabilidad criminal de acuerdo al artículo 10 CP. o a otra disposición legal, es obvio

${ }^{2}$ Araos Rojas, El sobreseimiento en materia penal (Universidad de Concepción, 1993), p. 48.

${ }^{3}$ La doctrina solía poner de relieve que lo que la ley exigía para que concurriera esta causa de sobreseimiento definitivo no era que el hecho no se hubiera verificado, sino que no aparecieran presunciones de que se hubiese verificado, lo cual es muy distinto. Así, López, L., Derecho procesal penal chileno (2a edición, Santiago, Ediar Editores, 1983), p. 226.

${ }^{4}$ Por todos, véase Mir Puig, Derecho penal. Parte general (7a edición, Montevideo - Buenos Aires, Editorial B de F, 2004), p. 145. 
que la causa de la letra a) sólo puede estar haciendo alusión a la falta de tipicidad del hechos.

La segunda causa de sobreseimiento definitivo se presenta cuando, resultando de la investigación que el hecho investigado efectivamente tuvo lugar y que es típico, los antecedentes recopilados permiten establecer la falta de participación del imputado en él ${ }^{6}$.

El tercer motivo de sobreseimiento definitivo tiene lugar cuando, resultando de la investigación que el hecho existió, que es típico y que tuvo participación en él el imputado, concurre una eximente que excluye la antijuridicidad del hecho -también llamada causa de justificación (como la legítima defensa y el estado de necesidad justificante, entre otras) - o la culpabilidad (por inimputabilidad, por desconocimiento de la ilicitud o por inexigibilidad de otra conducta) ${ }^{7}$, o bien, concurre una excusa legal absolutoria o se establece la ausencia de una condición objetiva de punibilidad que la ley contemple.

La cuarta causa de sobreseimiento definitivo se presenta cuando, resultando de la investigación que existió el hecho, que es típico, que el imputado tuvo participación en él, que además el hecho es antijurídico y culpablemente ejecutado, que no concurre ninguna excusa legal absolutoria y que se satisface la eventual condición objetiva de punibilidad que la ley exija, la responsabilidad penal se encuentra extinguida por algún motivo legal. Así sucedería, por ejemplo, si la acción penal ha prescrito.

La quinta causa alude a cualquier hecho sobreviniente que ponga término a la responsabilidad penal de acuerdo a la ley. Se trata de un motivo de sobreseimiento definitivo de amplio contenido, que se encuentra íntimamente vinculado con el anterior y en el que la doctrina incluye muchas hipótesis, tales como el desistimiento de la acción privada (artículo 401 CPP.), el abandono de dicha acción (artículo 402 CPP.) ${ }^{8}$, el pago de

${ }^{5}$ Así, Aguilar Aranela, Manual de Derecho procesal penal oral (Santiago, Editorial Metropolitana, 2004), I, p. 398. En el mismo sentido, pero aludiendo al Código de Procedimiento Penal, Fontecilla Riquelme, Derecho procesal penal (Santiago, 1943), I, p. 98; QueZada Meléndez, Derecho procesal penal (Santiago, Editorial Jurídica Ediar-Conosur, 1988), p. 228.

${ }^{6}$ Véase Lopez, L., Derecho procesal penal chileno, cit. (n. 2), p. 226, sosteniendo algo similar, pero referido al número $3^{\circ}$ del artículo 408 del Código de Procedimiento Penal.

${ }^{7}$ LÓPEZ, L., Derecho procesal penal chileno, cit. (n. 3), p. 226, aludiendo al número $4^{\circ}$ del artículo 408 del Código de Procedimiento Penal.

${ }^{8}$ Véase Araos Rojas, El sobreseimiento en materia penal, cit. (n. 2), pp. 88-93, pero aludiendo al número $6^{\circ} \mathrm{del}$ artículo 408 del Código de Procedimiento Penal. 
capital, intereses y costas en el delito de giro fraudulento de cheques ${ }^{9}$ y las situaciones del inciso $4^{\circ}$ del artículo 369 CP. ${ }^{10}$, entre otras.

La sexta y última causa de sobreseimiento definitivo alude a la cosa juzgada ${ }^{11} y$ encuentra su fundamento en que nadie que haya sido condenado, absuelto o sobreseído definitivamente por sentencia ejecutoriada puede ser sometido a un nuevo procedimiento penal por el mismo hecho, idea que aparece recogida en el segundo inciso del artículo $2^{\circ} \mathrm{CPP}$. bajo la denominación de "única persecución".

\section{SOLUCIÓN DEL PROBLEMA}

En esta parte del trabajo se intentará responder la interrogante central que lo motiva. Para facilitar el estudio del tema, imaginaremos un caso hipotético en el que al cerrar un fiscal la investigación por un determinado hecho, los antecedentes recopilados permiten concluir que el hecho no era constitutivo de delito o descartar toda participación del imputado en él y, al mismo tiempo, establecer que el eventual delito se encuentra prescrito.

Como se ha podido apreciar en el breve examen efectuado de los motivos de sobreseimiento definitivo del artículo 250 CPP., existe un orden lógico y preferente entre ellos. Esto no debe sorprender, toda vez que resulta común también en el derecho comparado ${ }^{12}$. Por eso, en la doctrina extranjera, Clariá Olmedo afirma que "los códigos modernos dan, como directiva para el tribunal, un orden para la consideración de las causales del sobreseimiento, el que deberá respetarse en lo posible. Es el siguiente: no comisión del hecho; falta de participación del imputado; ausencia de encuadramiento del hecho en alguna figura penal; mediación de una causa de justificación, inimputabilidad, inculpabilidad o una excusa absolutoria; causales extintivas" 13 .

Un argumento para sostener que el listado de causas de sobreseimiento definitivo constituye un orden de prelación, se encuentra en la discusión parlamentaria que precedió a la promulgación del Código Procesal Penal. Respecto del inciso final del artículo 250 de dicho Código-que, como se

${ }^{9}$ Véase Chahuán SARrás, Manual del nuevo procedimiento penal (3a edición actualizada y aumentada, Santiago, LexisNexis, 2007), p. 246.

${ }^{10}$ Aguilar Aranela, Manual de Derecho procesal penal oral, cit. (n. 5), p. 403.

${ }^{11}$ Cfr. López, L., Derecho procesal penal chileno, cit. (n. 3), p. 226, aunque aludiendo al número 7 o del artículo 408 del Código de Procedimiento Penal.

${ }^{12}$ Véanse, por ejemplo, los artículos 637 y 641 de la Ley de Enjuiciamiento Criminal española.

${ }^{13}$ Clariá Olmedo, Derecho Procesal Penal (actualizado por Jorge Raúl Montero, Buenos Aires, Rubinzal-Culzoni Editores, 2004), III, p. 15 (las cursivas son mías). 
ha visto, impide dictar sobreseimiento definitivo respecto de delitos que sean imprescriptibles o inamnistiables, conforme a tratados internacionales ratificados por Chile y que se encuentren vigentes-, el senador Fernández señaló que confunde el sobreseimiento con la prescripción, porque cuando aparezca la inocencia del imputado, el juez deberá sobreseer, aunque el delito sea imprescriptible ${ }^{14}$. Esta argumentación, que comparto, demuestra que la causa de sobreseimiento consistente en que aparezca la inocencia del imputado -que figura en la letra b) del citado artículo 250-, es de aplicación preferente a la que consiste en la extinción de la responsabilidad penal -que aparece después en el listado de motivos de sobreseimiento de dicha disposición, en la letra d)-. Esto me parece una confirmación de la existencia del mencionado orden de prelación.

Lo anterior permite sostener que si al finalizar la investigación del fiscal los antecedentes recogidos conducen a la conclusión de que el hecho investigado no era constitutivo de delito o que el imputado no tuvo ninguna participación en él, el sobreseimiento definitivo que se decrete en su favor debe fundarse en las causas de las letras a) o b) del artículo 250 CPP. $-y$ entre ambas causas, debe darse preferencia a la primera-,${ }^{15}$ a pesar de que los mismos antecedentes lleven también a la conclusión de que el hecho investigado está prescrito. El motivo de sobreseimiento definitivo de la letra d) del mencionado precepto presupone que se ha comprobado la existencia del hecho delictivo y la participación del imputado en él. La escasa doctrina que se ha pronunciado sobre el punto así lo ha señalado. Verbigracia, Araos Rojas sostiene, aludiendo al motivo número $5^{\circ}$ del artículo 408 del Código de Procedimiento Penal, muy similar a la letra d) del artículo 250 CPP., que "da por establecida la comisión del hecho delictivo por parte del imputado"16.

Existe otra razón más para avalar la conclusión de que un sobreseimiento definitivo no puede fundarse en la letra d) del artículo 250 CPP. por encontrarse prescrita la acción penal, cuando los antecedentes de la investigación demuestran que el hecho investigado no es constitutivo de delito o que la inocencia del imputado está claramente establecida. Como es sabido, conforme al artículo $94 \mathrm{CP}$., la determinación del plazo de prescripción de la acción penal depende de que nos encontremos frente a un crimen -caso en el cual la acción prescribe en diez o en quince años-, a un

${ }^{14}$ Véase Pfeffer Urquiaga, Código Procesal Penal anotado y concordado (2a edición, Santiago, Editorial Jurídica de Chile, 2006), p. 398.

${ }^{15}$ Véase Clariá Olmedo, Derecho Procesal Penal, cit. (n. 13), III, p. 16: “[...] debe darse preferencia a las causales objetivas, o sea considerar el encuadramiento penal antes que la participación".

${ }^{16}$ Araos Rojas, El sobreseimiento en materia penal, cit. (n. 2), p. 58. 
simple delito -caso en el cual el plazo de prescripción es de cinco años-, o a una falta -en cuyo caso la acción prescribe en seis meses-, por lo que para establecer si la acción penal se encuentra o no prescrita, debe primero determinarse que se trata de un hecho que satisface las exigencias típicas de un crimen, de un simple delito o de una falta. Pues bien, es imposible realizar esta operación si el hecho investigado no es constitutivo de delito por ser atípico. Sólo una vez comprobado que el hecho coincide con un tipo penal resulta posible determinar cuál es el plazo de prescripción. En este mismo sentido se pronuncia Clariá Olmedo, al sostener que "si el hecho no se ha cometido o no encuadra en una figura penal, no se advierte cómo puede concluirse, por ejemplo, sobre la prescripción" ${ }^{17}$.

Por otro lado, si un juez de garantía decretara un sobreseimiento definitivo por prescripción, cuando los antecedentes de la investigación del fiscal permiten concluir que los hechos investigados no existieron o que, de haber existido, ninguna participación en ellos tuvo el imputado, lesionaría el principio o presunción de inocencia ${ }^{18}$. Como en la investigación existirá certeza acerca de que no concurre el primero de los elementos que fundamentarían la responsabilidad penal del imputado -su participación en un hecho típico-, no resultará posible sobreseer por algún motivo que presuponga dicha responsabilidad ${ }^{19}$.

Puede añadirse lo siguiente. Es cierto que el artículo $168 \mathrm{CPP}$. faculta al fiscal para abstenerse de toda investigación cuando los antecedentes y datos suministrados permiten establecer que se encuentra extinguida la responsabilidad penal del imputado, decisión que debe ser fundada y someterse a la aprobación del juez de garantía. Sin embargo, esta disposición se halla dentro del párrafo $1^{\circ}$ (Persecución penal pública) del título I (Etapa de investigación) del libro II (Procedimiento ordinario) del mencionado Código. De ello se desprende que su ámbito de aplicación natural se encuentra en el inicio de la investigación. Consecuentemente, opera cuando al comenzar la investigación del fiscal, se tiene la certeza de que el hecho se encuentra prescrito o

${ }^{17}$ Clariá Olmedo, Derecho Procesal Penal, cit. (n. 13), III, p. 16.

${ }^{18}$ Sobre el principio de inocencia, véase, por todos, MAIER, Derecho procesal penal ( $2^{\mathrm{a}}$ edición, 1996, 3a reimpresión, 2004, Editores del Puerto, Buenos Aires), I, p. 490.

${ }^{19}$ Cfr. Carocca Pérez, El nuevo sistema procesal penal (Santiago, Editorial Jurídica La Ley, 2003), p. 199; El Mismo, Etapa intermedia o de preparación del juicio oral en el nuevo proceso penal chileno, en VV. AA., Nuevo proceso penal, Santiago (Editorial Jurídica ConoSur, 2000), p. 191, destacando la idea de que el principio o presunción de inocencia -en su vinculación con la institución del sobreseimiento temporal en el antiguo Código de Procedimiento Penal- exige que si no se ha logrado acreditar la responsabilidad penal, simplemente prevalezca la inocencia del imputado. 
de que la responsabilidad penal se ha extinguido por otro motivo. En estos casos parece razonable que no se dé curso al juicio. Pero cuando al inicio de la investigación no se tiene esa certeza, debe continuarse la investigación. Y si después de una extensa indagación se llega a tener la convicción de que ha transcurrido el plazo de prescripción, pero también la de que el hecho en realidad no ha tenido lugar, o que no es típico, o que el imputado no ha tenido participación en él, debe sobreseerse por alguna de estas últimas causas, por ser de aplicación preferente, como lo he dicho más arriba. Lo contrario constituiría una hipótesis de uso abusivo del proceso penal en el rol persecutorio del Estado. En efecto, todo imputado goza de la garantía del derecho a ser juzgado dentro de un plazo razonable. Pues bien, si el Estado decide, por falta de certeza sobre la prescripción de la acción penal, llevar adelante una larga investigación, la mencionada garantía obliga al Estado a que, al finalizar la instrucción, adopte una decisión concreta sobre la inocencia del imputado. Y si la investigación arroja como resultado que el hecho investigado no existió o que no era constitutivo de delito por ser atípico, o que el imputado no tuvo participación en él, la decisión que se adopte debe ser de mérito, un sobreseimiento por inexistencia del hecho delictivo o por total inocencia del imputado, por mucho que en esta etapa procesal se tenga claridad de que el plazo de prescripción ha vencido ${ }^{20}$.

También es verdad que, desde el punto de vista de la imposición de la pena, ninguna diferencia existe entre las diversas causas de sobreseimiento definitivo. Cualquiera sea el motivo por el que se sobresea definitivamente, la responsabilidad penal no podrá hacerse efectiva. Sin embargo, es evidente que existen varias razones para sostener que no da lo mismo la elección de la causa por la cual sobreseer ${ }^{21}$. Por ejemplo, un imputado en cuyo favor se ha dictado sobreseimiento definitivo fundado en la letra c) del artículo $250 \mathrm{CPP}$., en relación con el artículo 10 número $9^{\circ} \mathrm{CP}$., por haber concurrido la eximente de miedo insuperable -motivo de inexigibilidad de otra conducta-, podría pretender sustituir la causa, para vincularla con

\footnotetext{
${ }^{20}$ Sobre el tema, véase Franco, Abuso del proceso y prescripción de la acción penal, en Revista del Colegio de Abogados de la ciudad de Buenos Aires, 66 (2006) 1, pp. 6775.

${ }^{21}$ En este sentido, véase el oficio del Fiscal Nacional del Ministerio Público No 106, de 20 de marzo de 2001, Instructivo No 52, Sobre audiencias posteriores al cierre de la investigación, en Ministerio Público. Fiscalía NaCional, Reforma procesal penal. Instrucciones generales No 51 a 75, marzo - septiembre 2001 (Santiago, Editorial Jurídica de Chile, 2002), p. 33: "La resolución del juez es muy importante porque la causal del sobreseimiento fija la competencia del Tribunal Superior, en caso de apelación, $y$ además precisa los efectos jurídicos que se siguen del sobreseimiento definitivo, porque no es lo mismo sobreseer por estar extinguida la responsabilidad penal que hacerlo porque el hecho no es constitutivo de delito" (énfasis mío).
} 
la eximente de legítima defensa del artículo 10 número $4^{\circ} \mathrm{CP}$. -causa de justificación-, para excluir la responsabilidad civil derivada del hecho imputado $^{22}$. Otro tanto sucede en lo que respecta a la posible responsabilidad civil derivada del hecho de haberse llevado adelante la persecución penal. Si un fiscal solicita sobreseimiento definitivo por encontrarse extinguida la responsabilidad penal, no es indiferente que el tribunal acoja el sobreseimiento porque el hecho investigado no es constitutivo de delito, ya que ello podría llevar a tratar de hacer efectiva la responsabilidad civil del Ministerio Público y del propio fiscal ${ }^{23}$. Finalmente, también en lo que respecta a la determinación de los efectos que los sobreseimientos definitivos en juicios penales producen en materia civil tiene importancia la selección del motivo, como se desprende del artículo 179 CPC.

A lo anterior debe agregarse que es muy entendible y razonable que cualquier imputado prefiera ser sobreseído definitivamente por no haber existido el hecho investigado o por no haber tenido participación en él, antes que serlo por haber prescrito la acción para perseguir su responsabilidad penal, porque en este último caso su honra quedará mancillada. Piénsese que por algo el artículo 417 número $2^{\circ} \mathrm{CP}$. considera como una hipótesis de injuria grave la imputación de un crimen o simple delito prescrito $^{24}$. Esta es otra razón más para considerar que el listado de causas de sobreseimiento definitivo constituye un orden de prelación, en el que la concurrencia de los requisitos de una de ellas excluye la aplicación de las siguientes.

En conclusión, entre las distintas causas de sobreseimiento definitivo del artículo 250 CPP. existe un orden de prelación, de modo que el establecimiento de la concurrencia de los requisitos de una de ellas excluye la posibilidad de decretar el sobreseimiento por alguna de las siguientes. Si los antecedentes que arroje la investigación realizada por el fiscal demuestran que se encuentran establecidos los requisitos de dos o más motivos de sobreseimiento definitivo, el juez de garantía debe decretarlo fundado en aquella de las causas concurrentes que aparezca mencionada primero en el señalado orden.

[Recibido el 12 de septiembre y aceptado el 1 de octubre de 2008].

${ }^{22}$ Así, Horvitz Lennon - López Masle, Derecho procesal penal chileno (Santiago, Editorial Jurídica de Chile, 2002), I, p. 584.

${ }^{23}$ Véase el citado oficio No 106 del Fiscal Nacional del Ministerio Público, en Ministerio Público. Fiscalía Nacional, Reforma procesal penal, cit. (n. 21), p. 33.

${ }^{24}$ Cfr. Guzmán Dálbora, Artículos 93 a 105, en Politoff Lifschitz - Ortiz Quiroga (directores) - Matus Acuña (coordinador), Texto y comentario del Código Penal chileno (Santiago, Editorial Jurídica de Chile, 2002), I, p. 434. 


\section{BIBLIOGRAFÍA}

Aguilar Aranela, Manual de Derecho procesal penal oral (Santiago, Editorial Metropolitana, 2004).

Araos Rojas, El sobreseimiento en materia penal (Universidad de Concepción, 1993).

CAROcCa Pérez, El nuevo sistema procesal penal (Santiago, Editorial Jurídica La Ley, 2003).

Carocca Pérez, Etapa intermedia o de preparación del juicio oral en el nuevo proceso penal chileno, en VV. AA., Nuevo Proceso Penal (Santiago, Editorial Jurídica ConoSur, 2000).

CASTRO Jofré, Introducción al Derecho procesal penal chileno (Santiago, LexisNexis, 2006).

ChahuÁn SARrás, Manual del nuevo procedimiento penal (3a edición actualizada y aumentada, Santiago, LexisNexis, 2007).

Clariá Olmedo, Derecho procesal penal (edición actualizada por Jorge Raúl Montero, Buenos Aires, Rubinzal-Culzoni Editores, 2004).

Fontecilla Riquelme, Derecho procesal penal (Santiago, 1943).

Guzmán Dálbora, Artículos 93 a 105, en Politoff Lifschitz - Ortiz Quiroga (directores) - Matus Acuña (coordinador), Texto y comentario del Código Penal chileno (Santiago, Editorial Jurídica de Chile, 2002).

Horvitz Lennon - López Masle, Derecho procesal penal chileno (Santiago, Editorial Jurídica de Chile, 2002).

LÓpez, L., Derecho procesal penal chileno (2a edición, Santiago, Ediar Editores, 1983).

Franco, Abuso del proceso y prescripción de la acción penal, en Revista del Colegio de Abogados de la ciudad de Buenos Aires 66 (2006) 1.

MaIER, Derecho Procesal Penal ( $2^{a}$ edición, 1996, 3ª reimpresión, Editores del Puerto, Buenos Aires, 2004).

Ministerio Público. Fiscalía Nacional, Reforma procesal penal. Instrucciones generales $N^{o} 51$ a 75, marzo-septiembre 2001 (Santiago, Editorial Jurídica de Chile, 2002).

Mir Puig, Derecho penal. Parte general (7a edición, Montevideo - Buenos Aires, Editorial B de F, 2004).

Pfeffer Urquiaga, Código Procesal Penal anotado y concordado (2a edición, Santiago, Editorial Jurídica de Chile, 2006).

Quezada Meléndez, Derecho procesal penal (Santiago, Editorial Jurídica EdiarConoSur, 1988). 